\title{
BMJ Open Walkability and its association with walking/cycling and body mass index among adults in different regions of Germany: a cross-sectional analysis of pooled data from five German cohorts
}

\author{
Nadja Kartschmit (D) , ${ }^{1,2}$ Robynne Sutcliffe, ${ }^{3}$ Mark Patrick Sheldon, ${ }^{4}$ \\ Susanne Moebus, ${ }^{3}$ Karin Halina Greiser, ${ }^{1,5}$ Saskia Hartwig, ${ }^{1,2}$ Detlef Thürkow, ${ }^{6}$ \\ Ulrike Stentzel, ${ }^{7}$ Neeltje van den Berg, ${ }^{7}$ Kathrin Wolf, ${ }^{2,8}$ Werner Maier, ${ }^{2,9}$ \\ Annette Peters, ${ }^{2,8}$ Salman Ahmed, ${ }^{3}$ Corinna Köhnke, ${ }^{10}$ Rafael Mikolajczyk, ${ }^{1}$ \\ Andreas Wienke, ${ }^{1}$ Alexander Kluttig, ${ }^{1,2}$ Gavin Rudge ${ }^{4}$
}

To cite: Kartschmit N, Sutcliffe R, Sheldon MP, et al. Walkability and its association with walking/cycling and body mass index among adults in different regions of Germany: a cross-sectional analysis of pooled data from five German cohorts. BMJ Open 2020;10:e033941. doi:10.1136/ bmjopen-2019-033941

- Prepublication history for this paper is available online. To view these files, please visit the journal online (http://dx.doi org/10.1136/bmjopen-2019033941).

Received 29 August 2019 Revised 12 February 2020 Accepted 02 April 2020

Check for updates

(C) Author(s) (or their employer(s)) 2020. Re-use permitted under CC BY-NC. No commercial re-use. See rights and permissions. Published by BMJ.

For numbered affiliations see end of article.

Correspondence to Dr Alexander Kluttig; alexander.kluttig@uk-halle.de

\section{ABSTRACT}

Objectives To examine three walkability measures (points of interest (POI), transit stations and impedance (restrictions to walking) within $640 \mathrm{~m}$ of participant's addresses) in different regions in Germany and assess the relationships between walkability, walking/cycling and body mass index (BMI) using generalised additive models. Setting Five different regions and cities of Germany using data from five cohort studies.

Participants For analysing walking/cycling behaviour, there were 6269 participants of a pooled sample from three cohorts with a mean age of 59.2 years (SD: 14.3) and of them $48.9 \%$ were male. For analysing BMI, there were 9441 participants of a pooled sample of five cohorts with a mean age of 62.3 years (SD: 12.8) and of them $48.5 \%$ were male.

Outcomes (1) Self-reported walking/cycling (dichotomised into more than $30 \mathrm{~min}$ and $30 \mathrm{~min}$ and less per day; (2) BMI calculated with anthropological measures from weight and height.

Results Higher impedance was associated with lower prevalence of walking/cycling more than $30 \mathrm{~min} /$ day (prevalence ratio (PR): $0.95 ; 95 \% \mathrm{Cl} 0.93$ to 0.97 ), while higher number of $\mathrm{POI}$ and transit stations were associated with higher prevalence (PR 1.03; 95\% Cl 1.02 to 1.05 for both measures). Higher impedance was associated with higher $\mathrm{BMI}(\mathrm{B}: 0.15 ; 95 \% \mathrm{Cl} 0.04$ to 0.25 ) and a higher number of POI with lower BMI (B: $-0.14 ; 95 \% \mathrm{Cl}-0.24$ to 0.04). No association was found between transit stations and BMI (B: $0.005,95 \% \mathrm{Cl}-0.11$ to 0.12 ). Stratified by cohort we observed heterogeneous associations between $\mathrm{BMI}$ and transit stations and impedance.

Conclusion We found evidence for associations of walking/cycling with walkability measures. Associations for BMI differed across cohorts.

\section{INTRODUCTION}

At the United Nations High-Level Meeting on Non-Communicable Diseases in 2011,
Strengths and limitations of this study

- This is one of the first studies on the association between three domains of walkability (access to points of interest, transit stations and impedance as measure of connectivity) and walking and cycling behaviour and body mass index in Germany.

- Strengths of the study include that it covers various regions and cities in different parts of an entire European country.

- The low variability of the walkability measures in the study regions including mostly urban areas limits the interpretation of the results.

- Limitations of the walkability measures include that the variety of points of interest as well as the quality of bus and tram stops regarding frequency routes were not taken into account.

modifying the built environment has been proposed as one strategy for increasing physical activity for transport and recreational purposes. ${ }^{1}$ Walkability as characteristic of the built environment represents a modifiable population-based factor for promoting walking and cycling. ${ }^{2-4}$ Walking and cycling are inversely associated with obesity at population level. ${ }^{5}$

Several studies have found that more walkable neighbourhoods are associated with engaging in more walking and cycling and that people living in these neighbourhoods have a lower body mass index (BMI) ${ }^{6-9}$

The vast majority of studies focused on walking behaviour and mostly found positive associations with walkability. ${ }^{610}{ }^{11}$ Few studies examined cycling as outcome and results are inconsistent. ${ }^{12}$ Most studies that used a 
combined measure of walking and cycling found positive associations with walkability, ${ }^{12-14}$ indicating that better walkability could improve active transport in general. However, not for all built environmental features positive associations were found, which limits the evidence ${ }^{1516}$ and indicates that different environmental features could have different associations with walking on the one and cycling on the other hand. ${ }^{12}$ Additionally, although many studies on walkability and BMI indicate that BMI is lower the better walkability is, ${ }^{17-20}$ there are also studies that did not found any or only very weak associations between BMI and walkability. ${ }^{21-23}$ These inconsistencies could be due to the heterogeneity of walkability measures and methods used. $^{22} 23$ Moreover, most studies used self-reported measures of weight and height, ${ }^{17}$ resulting in a BMI that tends to be lower than the actual BMI. ${ }^{24}{ }^{25}$ Additionally, inconsistencies of the current findings may in part be due to little variability of walkability measures in some singlesite studies, which limits the generalisability of current results. ${ }^{26}$ Few studies have used a multicentre approach examining different regions and cities.

The advantage of multicentre studies over singlesite studies is that multicentre studies represent a more complete range of walkability variability when compared with single-site studies. Additionally, with multicentre studies, it is possible to examine if the positive associations between walkability and health outcomes apply in different regions. If this is the case, interventions that aim to improve walkability may gain more importance in health policies that aim to tackle non-communicable diseases. ${ }^{26}$

Findings of the multicentre studies showed that, generally, better walkability was associated with increased physical activity ${ }^{26-30}$ and lower BMI, although associations with BMI were rather small. ${ }^{29}$

The few studies that have used multicentre approaches mainly examined walkability across different countries and included mostly only one rather urban city per country, which may not be representative for the whole country. ${ }^{26-30}$ To be able to generalise the findings, studies are needed that examine the association between walkability and health outcomes in different regions of the same country, and including both, rural areas and urban cities of that country.

Traditionally, the methods of measuring walkability have used three domains. ${ }^{3}{ }^{31}$ First, there is impedance to walking; the presence of physical barriers or the absence of intersections causes a longer walking path/distance to reach a certain point that is nearer in Euclidian distance. ${ }^{32}$ Commonly, connectivity of route ways is used as measure of impedance. ${ }^{33}$ However, this measure does not explicitly take into account physical barriers, such as rivers, which may weaken the reliability of connectivity as a measure of impedance. ${ }^{32}$ Second, there is proximity to public transport access points. One of the reasons that people walk is to access public transport. ${ }^{34}$ Lastly, there is the presence of points people want to access (shops, banks, pharmacies, etc.). ${ }^{35}$
The consistency of how these three domains dominate walkability was highlighted by a systematic review of walkability methods. ${ }^{3}$ The aims of this multicentre study were to assess (1) walkability in different regions in Germany using three domains of walkability and (2) to examine the relationships of walkability with walking/cycling and BMI.

\section{METHODS}

\section{Study population}

We included cross-sectional data of five populationbased longitudinal cohort studies from different areas of Germany: the Dortmund Health Study (DHS) conducted in the city of Dortmund, the Heinz Nixdorf Recall study (HNR) conducted in the cities Mülheim, Bochum and Essen in Western Germany, the Cardiovascular Disease, Living and Ageing in Halle (CARLA) Study from the Eastern part of Germany, the Cooperative Health Research in the Region of Augsburg (KORA) S4 Survey from the South of Germany, and the Study of Health in Pomerania (SHIP) from the North-Eastern part. The CARLA, DHS and HNR studies randomly drawn samples from population registries stratified by age categories and sex. The KORA and SHIP study used a two-stage cluster sampling method by first selecting communities with cluster sampling and then performing age-stratified and sex-stratified random sampling. The years of the data collection of each sample in the analysis ranged between 2002 and 2014 (figure 1). ${ }^{36-42}$ Data of 6269 participants were included for analysing the relationship between walkability and walking/cycling after excluding missing values for exposure, outcome and covariates. Most missing values for exposure measures were observed in the SHIP cohort (54\% of the data that could not be geocoded occurred in the SHIP cohort for the BMI, and $85 \%$ for the walking/cycling sample). For examining the relationship between walkability and BMI, we included data of 9441 participants (figure 1). A description of the study regions is found in table 1 .

\section{Patient and public involvement}

Patients and public were not involved in the research process.

\section{Walkability measures}

Geographical information system (GIS) work was undertaken with ESRI ArcMap Desktop V.10.1 and V.10.4. ${ }^{43}$ We created a hexagonal sampling grid across each study region covering the municipal boundary from which participants had been recruited and a buffer of one kilometre beyond. We used sampling hexagons with sides of $1000 \mathrm{~m}$. We had to balance granularity of measurement with computational complexity; a larger hexagon would have led to more potential error in interpolation, but a smaller one would have been more intensive to calculate. By selecting the $1000 \mathrm{~m}$ hexagons and using the centroid of each hexagon as a sample point as well 


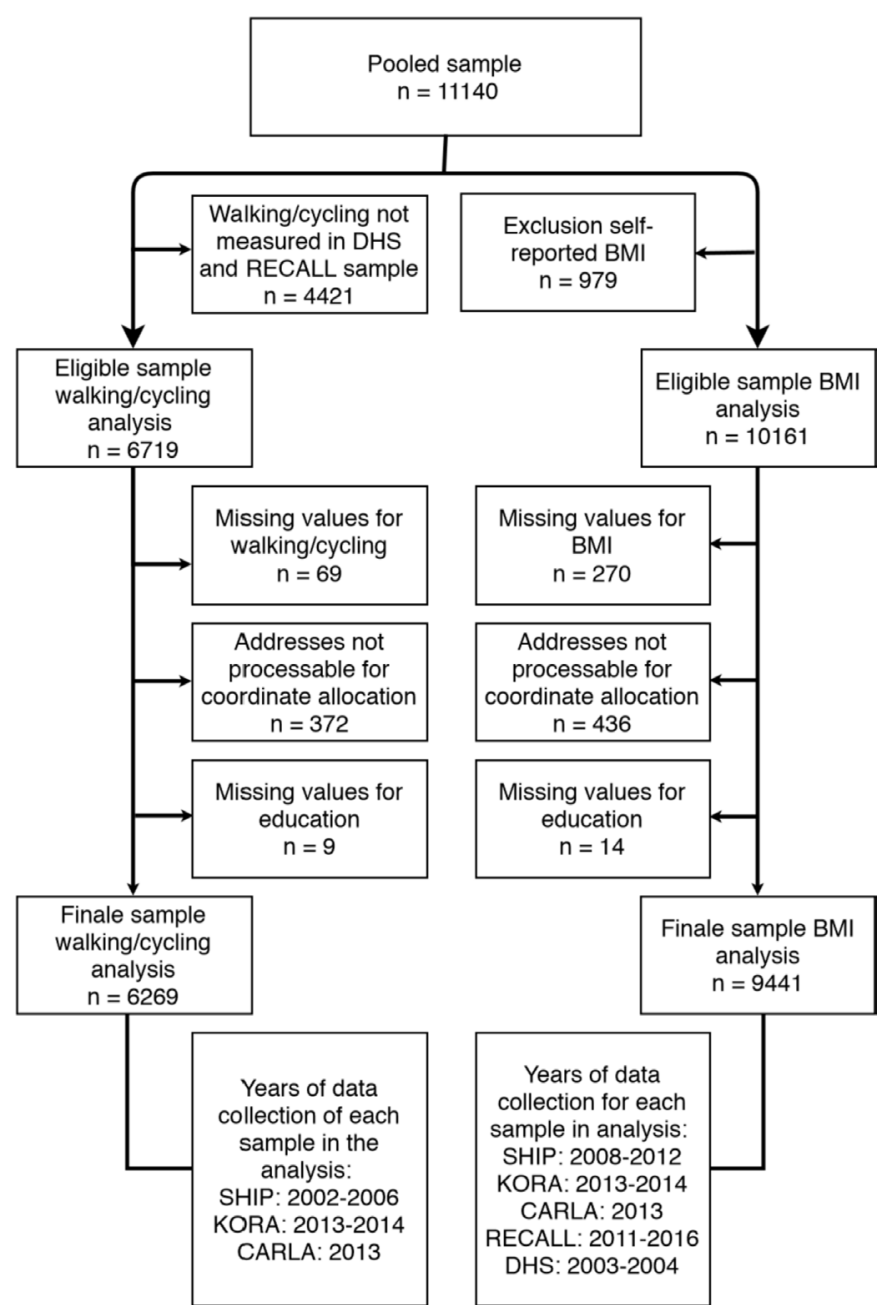

Figure 1 Sample flow chart. BMI, body mass index; CARLA, Cardiovascular Disease, Living and Ageing in Halle; DHS, Dortmund Health Study; KORA, Cooperative Health Research in the Region of Augsburg; SHIP, Study of Health in Pomerania.

as the six vertices, we had a distance of $500 \mathrm{~m}$ between each point. As we determined a short walk was as little over $500 \mathrm{~m}$, our interpolation estimation appeared to be scaled appropriately. We could have found an exact value for each dwelling for each walkability metric, however, it was not possible to share the address point outside of the cohort teams owing to data governance restrictions. Originally, making a surface was a pragmatic workaround for what was effectively a governance constraint, however, the utility of this method is that we can make generic surfaces to give a variable which can be used in many different types of study which can be used not only to estimate walkability of the area around a particular dwelling, but also when we want to correlate walkability with other area based measures.

The transport networks and points of interest (POI) for the cities were provided by OpenSteetMap (OSM) and processed using ArcGIS to create a network dataset. The walkability measures derived were the following:

POI: For each vertice and centroid of hexagons we calculated a polygon representing the area that could be reached within a walking distance of $640 \mathrm{~m}$, using roads, walkways and paths on the OSM network. The cut-off of $640 \mathrm{~m}$ was chosen because research carried out in London had proposed that the propensity to walk to access public transport declined rapidly after $640 \mathrm{~m}^{44}$ We took this a pragmatic definition of a short, accessible walking distance. We defined POI using OSM. For each polygon, we counted the POIs classified as 'shops' and added counts of all POIs classified as 'amenities' which were also tagged as either: 'ATM', 'bank', 'bar', 'Biergarten', 'café', 'fast food restaurant', 'pharmacy', 'pub', 'restaurant' or 'post office'.

Transit stations: We followed the same method to determine transit point availability as we did for POI. In the category 'highway' we captured all of the points tagged as 'bus stop', in the category 'railway' we captured all points tagged as 'stop', 'tram stop', 'station', 'subway entrance' 'entrance' or 'platform' and in the category 'amenity' we captured all the points tagged as 'bus station', 'train station' and 'ferry terminal'.

Impedance: typically, connectivity is used as a proxy measure for impedance. In our research, we used a slightly different approach. From the centroid of each hexagon we calculated six journeys in six different directions: Northeast, Northwest, West, Southwest, Southeast and East from the centre to each vertex of the hexagon. The six values vary according to ease of access in the various directions with higher values reflecting a lack of ease of walking in that direction (figure 2). For example, if a point which was $1000 \mathrm{~m}$ Euclidian distance away was accessible by a journey of $2300 \mathrm{~m}$, this was 2.3 times larger than the Euclidian distance. A comparable $1000 \mathrm{~m}$ Euclidian distance that can be walked in $1050 \mathrm{~m}$ clearly has fewer barriers.

Each of the metrics was interpolated between the points to construct a surface. We used kriging method to interpolate values between the hex points using a Gaussian regression process. Figure 3 shows the impedance for the HRS study area. We intersected all created surfaces with the residential addresses of our cohort participants. All walkability surfaces were created in 2016 .

\section{Outcomes}

Walking/cycling included walking and cycling for transport and recreational purposes. For KORA, two items according to walking and cycling from the WHO MONICA Project questionnaire were combined into one item. ${ }^{45}$ For CARLA and SHIP, one item from the Baecke questionnaire regarding walking and cycling for transport and recreation was considered. ${ }^{46}$ We dichotomised the variable into $>30 \mathrm{vs} \leq 30 \mathrm{~min}$ per day of walking or cycling for transport or recreational purposes. We chose this cut-point because previous research has shown that engaging in physical activity for about $30 \mathrm{~min}$ or more per day has beneficial effects on health outcomes and may be achieved by walking/cycling to and from transit stations/ POI. ${ }^{347}$ 


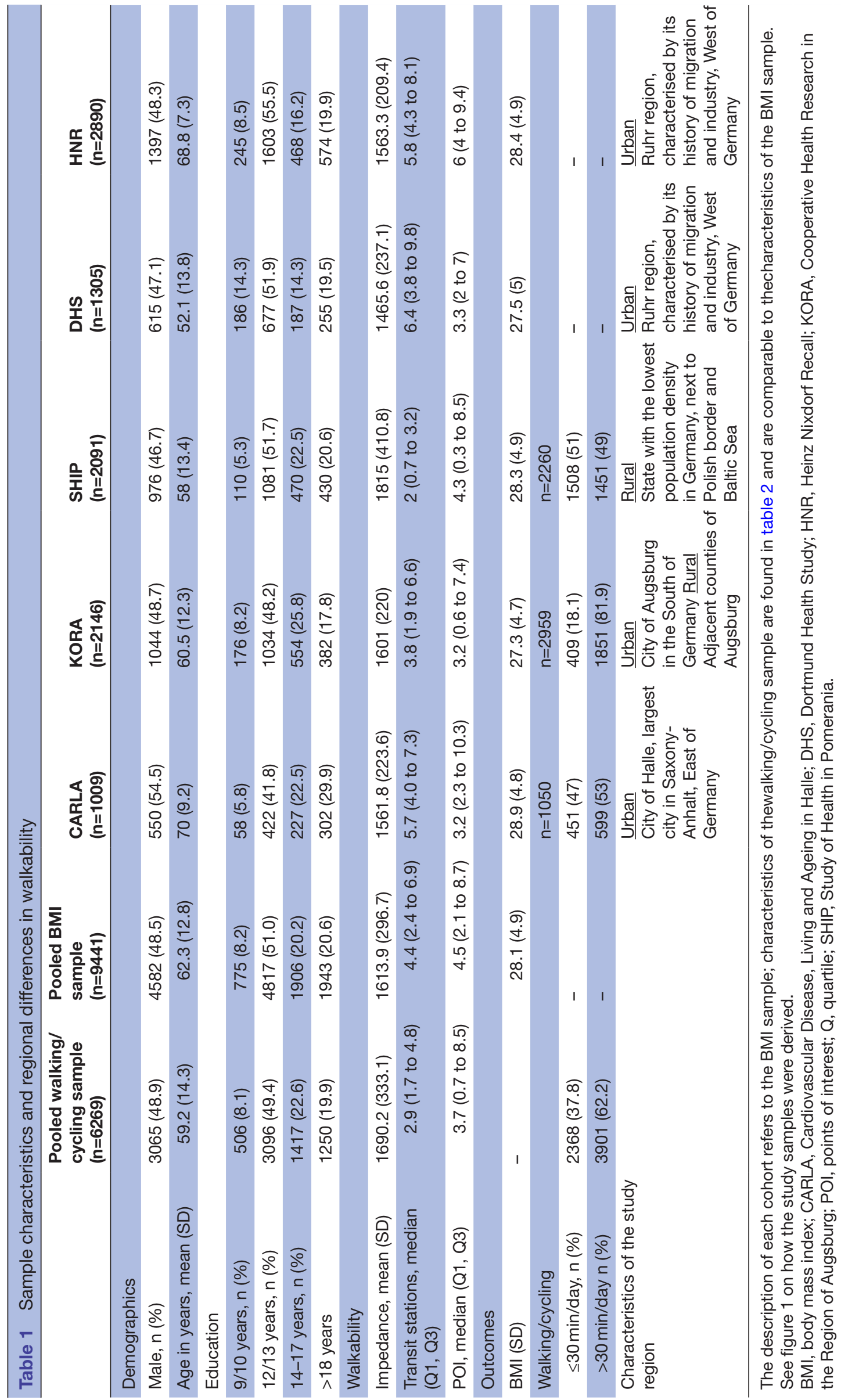




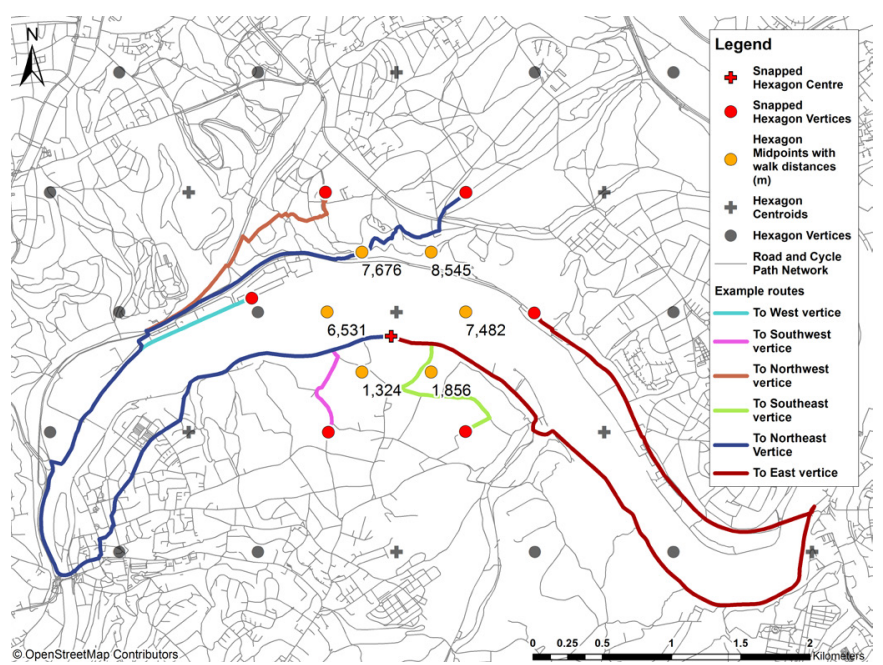

Figure 2 Impedance calculation of walk distances for one hexagon centroid and its vertices in part of the Heinz Nixdorf Recall study region adjacent to river Ruhr

BMI was calculated from height and weight, which were objectively measured according to comparable protocols in all five studies.

\section{Sociodemographic covariates}

Following covariates were derived from self-reported data from standardised questionnaires: sex (male and female), age in years and years of education. We classified the variable years of education on the basis of the International Standard Classification of Education $1997 .{ }^{48}$ School years and years of vocational education are both included in the total number of years with the categories: $9 / 10$ years, 12/13 years, $14-17$ years and 18 and more years.

\section{Statistical analysis}

Participant characteristics were summarised as mean (SD) for normally distributed continuous variables, median

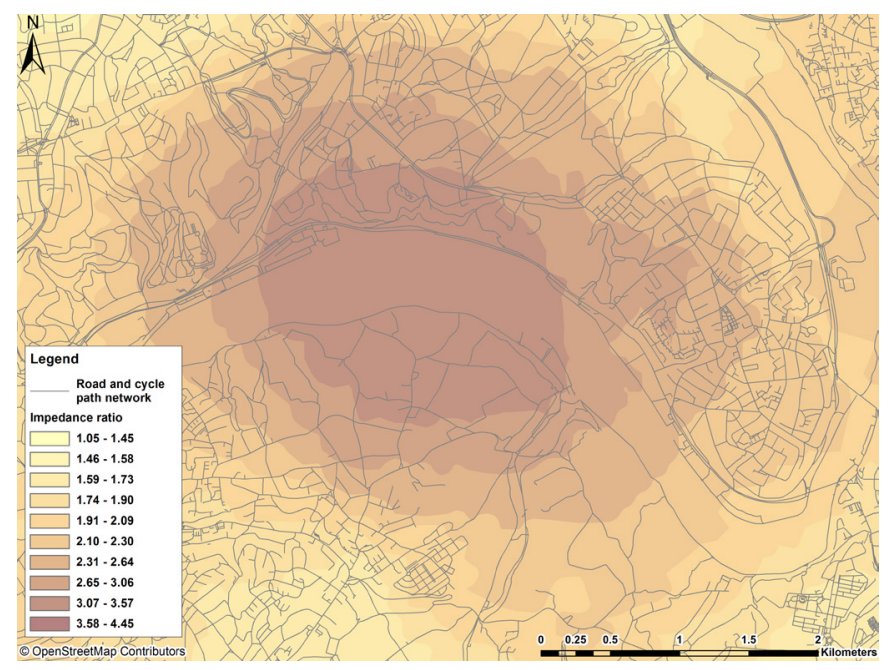

Figure 3 Impedance layer for a part of the Heinz Nixdorf Recall study region with the river Ruhr with walk distance values interpolated using kriging
(IQR) for non-normally distributed variables and number (percentage) for categorical variables.

Generalised additive models (GAMs) were used for analysing the association between each walkability measure and the outcome of interest. The shape of the relationship was estimated using thin-plate splines. For the dichotomous outcome walking/cycling, the GAMs used binomial variance and log link function; for the continuous outcome BMI, we used Gaussian distribution. For smoothness selection, restricted maximum likelihood was considered. ${ }^{49}$

We tested nonlinearities in the relationship between walkability measures and outcomes based on Akaike information criterion (AIC) values. A difference in AIC $\geq 10$ units comparing the models with linear versus nonlinear term was considered meaningful. ${ }^{50}$ Walkability measures were included as linear terms, since no nonlinearities were found. Age was included as nonlinear term in all models. We z-standardised the measures for better comparability.

In order to assess if associations differed across cohorts, we stratified by cohort. Due to regional differences in the completeness of OSM data, measurement error of the exposure is likely to differ across cohorts, which could result in spurious interactions, so we did not test interactions. ${ }^{51}$

In a sensitivity analysis, we examined walking and cycling as separate outcomes for the KORA cohort. Although cycling and walking share some similarities, there are also differences, for example, regarding distance to travel and travel speed, and this could result in different associations with walkability measures. ${ }^{12}$

All models were adjusted for age, sex, cohort, and education. Analysis was conducted with SAS V.9.4 ${ }^{52}$ and R-Studio V.3.4. $4^{53}$ with the package 'mgvc'. ${ }^{49}$

\section{RESULTS}

\section{Sample characteristics}

Both sexes were equally represented in the pooled sample. The participants in the pooled sample had a mean age of about 60 years and a mean BMI of $28 \mathrm{~kg} / \mathrm{m}^{2}$, and half of them had 12/13 years of education. Mean impedance was lowest and median transit stations were highest in the highly urbanised DHS cohort, while mean impedance was highest and median transit stations were lowest in the rural area of the SHIP cohort. Median POI was highest in the HNR cohort and similar in all other cohorts. Overall, exposure contrast was low in the cohorts, as seen by visualising the surfaces of the measures with the address points. About $60 \%$ of the pooled walking/cycling sample reported to walk/cycle more than $30 \mathrm{~min}$ per day. This percentage was highest in the KORA and lowest in the SHIP cohort (tables 1 and 2).

\section{Associations between walkability, walking/cycling and BMI}

Higher impedance was associated with lower prevalence of walking/cycling $30 \mathrm{~min} /$ day, while higher numbers of 
Table 2 Sample characteristics walking/cycling sample by cohort

CARLA $(n=1050) \quad$ KORA $(n=2260) \quad$ SHIP $(n=2959)$

\begin{tabular}{|c|c|c|c|}
\hline \multicolumn{4}{|l|}{ Demographics } \\
\hline Male, n (\%) & $554(52.8)$ & $1093(48.4)$ & $1418(47.9)$ \\
\hline Age in years, mean (SD) & $69.8(9)$ & $60.2(12.3)$ & $54.8(15.2)$ \\
\hline \multicolumn{4}{|l|}{ Education } \\
\hline 9/10 years, $\mathrm{n}(\%)$ & $58(5.5)$ & $185(8.2)$ & $263(8.9)$ \\
\hline 12/13 years, $\mathrm{n}(\%)$ & $445(42.4)$ & $1096(48.5)$ & $1555(52.6)$ \\
\hline $14-17$ years, $n(\%)$ & $236(22.5)$ & $580(25.7)$ & $601(20.3)$ \\
\hline$>18$ years & $311(29.6)$ & $399(17.7)$ & $540(18.3)$ \\
\hline \multicolumn{4}{|l|}{ Walkability } \\
\hline Impedance, mean (SD) & $1561.9(226.3)$ & $1602.7(12.3)$ & $1802.6(394.7)$ \\
\hline Transit stations, median (Q1, Q3) & $5.7(4-7.3)$ & $3.7(10.9-6.6)$ & $2.1(0.8-3.2)$ \\
\hline POI, median (Q1, Q3) & $3.2(2.3-10.3)$ & $3.2(0.5-7.2)$ & $4.4(0.4-8.5)$ \\
\hline \multicolumn{4}{|l|}{ Walking/cycling } \\
\hline$\leq 30$ minutes/day, $\mathrm{n}(\%)$ & $451(47)$ & $409(18.1)$ & $1508(51)$ \\
\hline$>30 \mathrm{~min} /$ day $\mathrm{n}(\%)$ & $599(53)$ & $1851(81.9)$ & $1451(49)$ \\
\hline
\end{tabular}

CARLA, Cardiovascular Disease, Living and Ageing in Halle; KORA, Cooperative Health Research in the Region of Augsburg; POI, points of interest; SHIP, Study of Health in Pomerania.

POI and transit stations were associated with higher prevalence (table 3). This association was consistent across cohorts (figure 4A).

The sensitivity analysis for walking and cycling as separate outcome measures showed similar estimates for walking as well as for cycling. The CI for cycling as outcome were larger including the null effect for impedance and POI, while this was not the case for walking as outcome (table 4).

Higher impedance was associated with an increase in BMI (table 3 ). When stratified by cohort, higher impedance was associated with an increase in BMI for all cohorts except for the HNR cohort, where it was associated with a decrease (figure 4B).

We found no association between number of transit stations and BMI (table 3). When stratified by cohort, we observed for DHS and HNR slightly increased and for SHIP slightly decreased point estimates with wide CI and no associations in the other cohorts (figure 4B).
BMI decreased with increasing POI (table 3). When stratified by cohort, for SHIP and CARLA we revealed decreased estimates and no associations in the other cohorts (figure 4B).

\section{DISCUSSION}

In this cross-sectional multicentre study, we analysed the association of three measures of walkability and walking/ cycling and BMI. The walkability measures were related to walking/cycling, but associations with BMI were not consistent. In the rural SHIP cohort, better walkability was associated with higher prevalence of walking/cycling and lower BMI. The associations of walkability with the outcomes were less pronounced and inconsistent in highly urbanised areas, like the DHS and HNR cohorts.

\section{Walkability and walking/cycling}

Various systematic reviews ${ }^{654-56}$ found evidence for a positive relationship between total walking for transport

Table 3 Association between walkability and outcomes

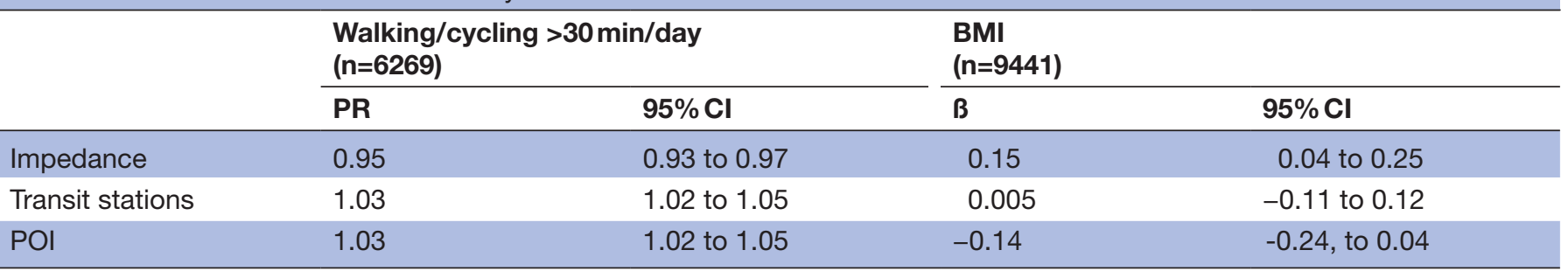

Models are adjusted for age, sex, education and cohort; walkability measures are z-standardised.

BMI sample: SD for impedance=296.7, SD for transit stations=4.1, SD for $\mathrm{POI}=7.1$; walking/cycling sample: SD for impedance=333.1, SD for transit stations=3.4, SD for $\mathrm{POI}=7.0$. Reference category for walking/cycling $>30 \mathrm{~min} /$ day is walking/cycling $\leq 30 \mathrm{~min} / \mathrm{day}$.

$\mathrm{BMI}$, body mass index; POI, points of interest; PR, prevalence ratio. 
Associations between walkability and walking/cycling by cohort Walkability measure PR

Impedance

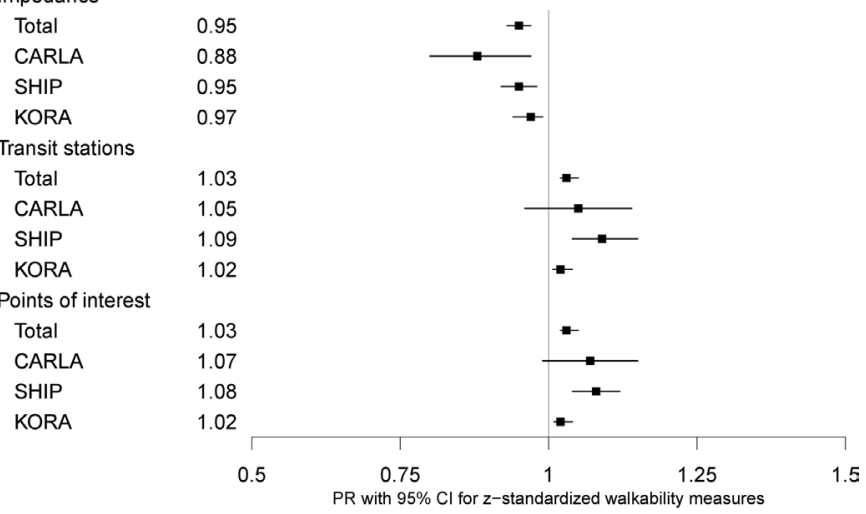

Associations between walkability and body mass index by cohort Walkability measure Beta

Impedance

$\begin{array}{lr}\text { Total } & 0.15 \\ \text { CARLA } & 0.33 \\ \text { SHIP } & 0.23 \\ \text { KORA } & 0.22 \\ \text { DHS } & 0.13 \\ \text { HNR } & -0.21 \\ \text { Transit stations } & \\ \text { Total } & 0.005 \\ \text { CARLA } & -0.03 \\ \text { SHIP } & -0.25 \\ \text { KORA } & -0.02 \\ \text { DHS } & 0.22 \\ \text { HNR } & 0.12 \\ \text { Points of interest } & \\ \text { Total } & -0.14 \\ \text { CARLA } & -0.29 \\ \text { SHIP } & -0.34 \\ \text { KORA } & -0.04 \\ \text { DHS } & -0.02 \\ \text { HNR } & -0.02 \\ & \end{array}$

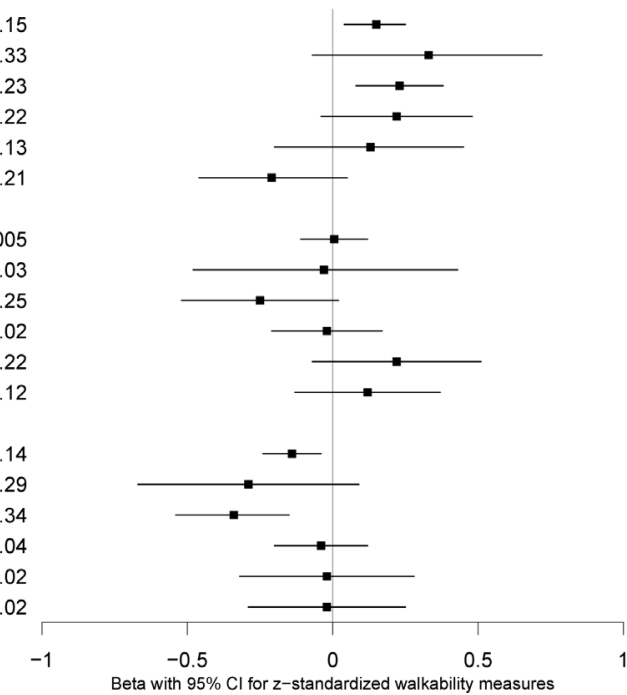

Figure 4 (A) Association between walkability and walking/ cycling by cohort $(B)$ association between walkability and body mass index by cohort. CARLA, Cardiovascular Disease, Living and Ageing in Halle; $\mathrm{Cl}$, confidence interval; DHS, Dortmund Health Study; HNR, Heinz Nixdorf Recall; KORA, Cooperative Health Research in the Region of Augsburg; PR, prevalence ratio; SHIP, Study of Health in Pomerania.

and land-use mix, public transport and street connectivity, which supports the result of our study. In our study, walking/cycling decreased with increasing impedance, which was consistent with our hypothesis, that

impedance may represent a lack of ease of walking/ cycling as a measure of insufficient connectivity. Associations observed in our study were small with wide CI, which might be due to low variability of walkability in our cohorts. Commonly, stronger effects for walkability on walking are observed in studies conducted in the USA and Australia, since these countries might be generally less walkable than European countries and contrasts of walkability might be much larger than in Europe, which might explain the rather small associations found in our study. ${ }^{27} 3055$ Even though we included different areas of a whole country to increase variability of walkability measures, it may be that differences between walkability within the country are not large enough to produce large differences in outcome measures. ${ }^{22}$

We were not able to analyse walking and cycling separately for the whole sample. Kerr et $a l^{27}$ and Muhs et $a l^{12}$ demonstrated the importance of analysing these activities separately, because highly walkable areas could support walking, but not cycling, since, for example, pedestrian walkways could hinder favoured cycling speed. However, in a sensitivity analysis for the KORA cohort, we could show that the effect estimates for walking and cycling were comparable, although less precise and less consistent for cycling with CI including 1 . That we still found an association for the whole sample when combining the measures may be due to the skewed distribution towards people who reported to walk when compared with people who reported to cycle. ${ }^{12}$

Additionally, we were not able to distinguish between walking/cycling for recreational or for transport purposes, which could also explain the rather small associations. A river could have a positive influence on walking for recreation, but a negative influence on walking for transport, since it could represent a barrier. ${ }^{57-59}$

\section{Walkability and BMI}

Consistent with some previous research, POI and impedance were associated with lower BMI in the pooled analysis. ${ }^{60-62}$ However, although impedance and POI were associated with lower BMI in the pooled analysis, the relationship between these two measures and BMI was inconsistent across cohorts. Hence, the results of the pooled analysis should be interpreted with caution, since the association between walkability and BMI may differ

Table 4 Association between walkability and walking and cycling separately in the KORA cohort

\begin{tabular}{|c|c|c|c|c|}
\hline & \multicolumn{2}{|c|}{ Walking $>30 \mathrm{~min} /$ day } & \multicolumn{2}{|c|}{ Cycling $>30 \mathrm{~min} /$ day } \\
\hline & PR & $95 \% \mathrm{Cl}$ & PR & $95 \% \mathrm{Cl}$ \\
\hline Impedance & 0.95 & 0.92 to 0.99 & 0.94 & 0.85 to 1.03 \\
\hline $\mathrm{POI}$ & 1.05 & 1.02 to 1.07 & 1.05 & 0.99 to 1.11 \\
\hline
\end{tabular}

Models are adjusted for age, sex and education; walkability measures are z-standardised. Seventy-four per cent of the sample reported to walk more than 30 min per day and $32 \%$ reported to cycle more than 30 min per day.

KORA, Cooperative Health Research in the Region of Augsburg; POI, points of interest; PR, prevalence ratio. 
depending on the setting. For transit stations, we have found no associations with BMI, neither in the pooled nor in stratified analysis. Likewise, previous studies found inconsistencies in the relationship between BMI and walkability measures, indicating no associations and some even found associations in the unexpected direction. ${ }^{63-65}$

The finding that better walkability is associated with increased walking and cycling, but not consistently with lower BMI, is supported by the majority of previous research. ${ }^{6} 102223$ This finding seems counterintuitive, since increased activity should lead to decreased BMI. However, many factors determine $\mathrm{BMI}^{66} 67$ and physical activity alone cannot explain BMI. ${ }^{66}$ Diet might be more important in determining BMI than activity. ${ }^{68}$ The slightly higher activity might not be sufficient in order to have an impact on BMI, given other determinants of BMI. ${ }^{69}$ Our study supports this possible explanation. The measure of walking/cycling that we have used did not take into account the intensity of walking/cycling. Even though POI is associated with an increased walking/cycling behaviour, this increase might not be strong enough to have any effect on BMI, as seen in the KORA cohort, where POI were associated with increased walking/ cycling, but not with decreased BMI.

\section{Strengths and limitations}

We decided to use POI density in walk polygons as it explicitly linked an area of known walkability to locations of amenities determined by people locally. However, we did not explicitly measure the variety of POI. According to the transit point metric, the weakness is that it does not reflect the frequency of transport or the choice of destination. In addition, we did not weight them in any way, so a railway station had equal weight as a bus stop. Our method of capturing impedance is the most radical change compared with other research methods. Connectivity and intersection density have traditionally been used because highly connected networks allow quick and easy access to the local area. However, we wanted a measure that compared the ease of accessing a nearby point with the Euclidian distance. By plotting six journeys around our points in different directions and anchoring those with reference to the Euclidian distance, we felt that we were able to get a more reliable measure than connectivity alone. The method appears to have face validity as we can clearly see higher impedance around rivers, rail yards and other physical barriers. While there is consensus in the built environment literature that impedance is an important domain of walkability, there is no consensus on how this should be measured. ${ }^{32}$ In this study, we intuited that our measure was sensitive to impedance in different directions from a series of sample points and so was better than simply using the density of route intersections in the area, or indeed other possible measurement methods. We are planning a validation study to unpick this issue in more detail.

The selection of $640 \mathrm{~m}$ to define a 'short walk' was determined in the absence of sufficient evidence. We do not know whether this propensity is generalisable to a different country. We could intuit that the German population walks more than the British one, as Germans take more public transport journeys annually per capita (177 compared with 147$)^{70}$ which could indicate that we needed larger walk polygons. Additionally, what a 'short walk' defines could be different according to environmental attributes and subgroups (eg, younger vs older adults) ${ }^{71}$ A further issue is the extent to which crowdsourced GIS data is reliable. However, studies showed that OSM data compared favourably with state and commercial sources in urban areas, although coverage in rural areas is acknowledged to be more variable in OSM data. ${ }^{72}$

For 372 and 436 participants, respectively, walkability values could not be computed. Most of the missing walkability values occurred just in the SHIP study, which could have introduced a bias, since this was also the cohort with the poorest walkability measures.

The walkability measures were computed in the year 2016, years after information of participants was collected, so changes in walkability measures during that time could have resulted in misclassification. However, when, for example, new businesses were opened, it is likely that these would be in areas where already some businesses existed, so that walkable areas would stay walkable or improve, and less walkable areas would stay less walkable or generally improve less.

It was not feasible to account for clusters in the data of the included cohort studies due to lack of a suitable arealevel variable available for Germany. Statistically, there could be dependencies among people living in the same barrier or neighbourhood. Not accounting for possible clusters in the data could reduce variance and statistical power. $^{74}$

We took into account three measures that have been proved to be important dimensions of walkability. ${ }^{3}$ However, we did not take into account, for example aesthetics and safety, measures that are also associated with walking/cycling behaviour. ${ }^{31}$ The observed results could strongly be influenced by the measures we have used and a POI in an area might have a different association with walking/cycling according to the characteristics of other walkability measures in the same area.

We have used self-reported walking/cycling as one of our response variables. Measuring walking/cycling with an accelerometer would have been a much more precise and would have eliminated social desirability bias that is inherent in self-report of physical activity.

Due to the pooling of the cohorts, the confounder adjustment set is quite limited. Residual confounding is highly likely, as we only adjusted for few variables, but, for example, not for income or occupation as other parts of socioeconomic status. Additionally, we were not able to adjust for residential self-selection, since this information was not available, which could have biased the results away from the null. However, previous research has shown that neighbourhood self-selection only yield minor changes in the results. ${ }^{75-77}$ 
Since z-scores were calculated across cohorts, the estimates might be confounded by rurality, because the SHIP cohort comprise poorer exposure values. However, we adjusted for cohort to correct for this possible confounding. As stated earlier, the coverage of OSM data in rural versus urban areas may differ. Differential measurement error associated with regional differences in the completeness of OSM data could have some influence on the main effects and hence result in biased estimates. However, it is assumed that the differential measurement errors from the different cohorts cancel out (at least partly) and therefore have little to no influence on the main effects.

BMI was based on standardised measurements of weight and height and not on self-report and social desirability bias did not occur, representing an important asset.

This work has implications for policy. The observed effect of walkability measures on walking/cycling was small. However, changes in walkability changes walking and cycling behaviour on a population level, since everyone is affected by these changes. People with no or very few transit stations near their residence could benefit from extending public transportation. Considering the impedance measure, additional paths in low-connected areas may contribute to enhancement in walking and cycling.

Due to the inconsistency in the findings, a conclusion on the association between walkability and BMI cannot be drawn. Our results indicate that associations of walkability on BMI could differ between rural and urban areas, highlighting the need to investigate these discrepancies. However, we showed that higher walkability is associated with more walking/cycling. Walking and cycling for transport or recreation can easily be incorporated into the individuals' daily lives, when neighbourhoods are supportive of such behaviours.

\section{Author affiliations}

${ }^{1}$ Institute of Med. Epidemiology, Biometrics and Informatics, Martin-Luther-

University Halle-Wittenberg, Halle, Germany

${ }^{2}$ German Center for Diabetes Research (DZD), Neuherberg, Germany

${ }^{3}$ Centre for Urban Epidemiology, University Clinics Essen, Essen, Germany

${ }^{4}$ Institute of Applied Health Research, University of Birmingham, Birmingham, UK

${ }^{5}$ German Cancer Research Centre, Heidelberg, Baden-Württemberg, Germany

${ }^{6}$ Institute of Geosciences and Geography, Martin-Luther-University Halle-Wittenberg,

Halle, Germany

${ }^{7}$ Institute for Community Medicine, University Medicine Greifswald, Greifswald, Germany

${ }^{8}$ Institute of Epidemiology II, Helmholtz Zentrum München, Neuherberg, Germany ${ }^{9}$ Helmholtz Zentrum München, German Research Center for Environmental Health, Institute of Health Economics and Health Care Management, Neuherberg, Germany ${ }^{10}$ Institute of Epidemiology and Social Medicine, University of Münster, Münster, Nordrhein-Westfalen, Germany

Acknowledgements We thank all participants of the cohort studies and all members of the study teams who participated in the recruitment, data collection, data management, and analysis. We thank all OpenStreetMap contributors. Parts of this work were presented orally and as abstract at the 13. Annual Conference of the German Epidemiological Association (DGepi), 26-28. September 2018 and orally during the Epidemiology of Chronic Diseases Research and Training Summer School, 3-7. September in Hawassa, Ethiopia.
Contributors SH planned the study and reviewed the manuscript. NK conducted the statistical analysis and wrote the manuscript. GR and MPS planned the study, devised, and created the walkability measures. DT assigned the walkability measures to the CARLA participants. AK and KHG planned and coordinated the CARLA study and devised the walkability study. US, NvdB, KW, WM, AP, CK and SA provided data and reviewed the manuscript. GR, MPS, AK, KHG, RM, RS and SM reviewed the manuscript and contributed to the discussion. GR contributed to the methods and discussion part. AW advised on the statistical analysis. All authors have read the manuscript, agreed the work is ready for submission to a journal, and accept responsibility for the manuscript's contents.

Funding This work was supported by the Competence Network Diabetes Mellitus of the German Federal Ministry of Education and Research (BMBF, grant 01Gl1110C) and the Competence Network Obesity (BMBF, grant 01Gl1121B). The Cardiovascular Disease, Living and Ageing in Halle (CARLA) Study was supported by a grant from the Deutsche Forschungsgemeinschaft as part of the Collaborative Research Centre 598 'Heart failure in the elderly — cellular mechanisms and therapy' at the Medical Faculty of the Martin-Luther-University Halle-Wittenberg, by a grant of the Wilhelm-Roux Programme of the Martin-Luther-University HalleWittenberg; by the Ministry of Education and Cultural Affairs of Saxony-Anhalt, and by the Federal Employment Office. The Study of Health in Pomerania (SHIP) is part of the Community Medicine Research net (http://www.community-medicine.de) at the University of Greifswald, Germany. Funding was provided by grants from the German Federal Ministry of Education and Research (BMBF, grant 01ZZ0403); the Ministry for Education, Research and Cultural Affairs; and the Ministry for Social Affairs of the Federal State of Mecklenburg-West Pomerania. The Heinz Nixdorf Recall Study (HNR) was generously supported by the Heinz Nixdorf Foundation (Germany). The study is also supported by the German Ministry of Education and Science. The KORA research platform (KORA, Cooperative Health Research in the Region of Augsburg) was initiated and financed by the Helmholtz Zentrum München-German Research Center for Environmental Health, which is funded by the German Federal Ministry of Education and Research and by the State of Bavaria. Furthermore, KORA research was supported within the Munich Centre of Health Sciences (MC-Health), Ludwig-Maximilians-Universität, as part of LMUinnovativ. The Dortmund Health Study (DHS) was supported by unrestricted grants to the University of Münster from the German Migraine and Headache Society and a consortium formed with equal shares by Allmiral, Astra-Zeneca, Berlin-Chemie, Boehringer Ingelheim Pharma, Boots Healthcare, GlaxoSmithKline, Janssen Cilag, McNeil Pharmaceuticals, MSD Sharp \& Dohme and Pfizer. Gavin Rudge and Mark Patrick Sheldon were funded by the National Institute for Health Research (NIHR) Collaborations for Leadership in Applied Health Research and Care the West Midlands.

Disclaimer The views expressed are those of the author(s) and not necessarily those of the NHS, the NIHR or the Department of Health.

Map disclaimer The depiction of boundaries on the map(s) in this article do not imply the expression of any opinion whatsoever on the part of BMJ (or any member of its group) concerning the legal status of any country, territory, jurisdiction or area or of its authorities. The map(s) are provided without any warranty of any kind, either express or implied.

Competing interests None declared.

Patient and public involvement Patients and/or the public were not involved in the design, or conduct, or reporting, or dissemination plans of this research.

Patient consent for publication Not required.

Ethics approval The studies have been conducted according to the principles of the Declaration of Helsinki and have been approved by local ethics committees and written informed consent has been obtained from all participants. KORA (Helmholtz Zentrum München): Ethics committee of the Bavarian Medical Association and the Bavarian commissioner for data protection and privacy (approval number: 06068). CARLA (Martin-Luther-University): Ethics committee of the Medical Faculty of Martin-Luther-University and the state data privacy commissioner of Saxony-Anhalt (approval number: 164/12.10.05/1). HNR (University Clinics Essen): Ethics committee of the Medical Faculty of the University Duisburg-Essen (approval number: 99-69-1200)DHS (University of Münster): Ethics committee of the University of Münster and the Westphalian Chamber of Physicians in Münster (approval number: 3V II Berger). SHIP (Ernst-Moritz-Arndt University Greifswald): Ethics committee of the Medical Faculty of the Ernst-Moritz-Arndt University Greifswald (approval number: III UV 73/01/BB 39/09).

Provenance and peer review Not commissioned; externally peer reviewed.

Data availability statement No data are available. 
Open access This is an open access article distributed in accordance with the Creative Commons Attribution Non Commercial (CC BY-NC 4.0) license, which permits others to distribute, remix, adapt, build upon this work non-commercially, and license their derivative works on different terms, provided the original work is properly cited, appropriate credit is given, any changes made indicated, and the use is non-commercial. See: http://creativecommons.org/licenses/by-nc/4.0/.

ORCID iD

Nadja Kartschmit http://orcid.org/0000-0002-5756-5542

\section{REFERENCES}

1 Beaglehole R, Bonita R, Horton R, et al. Priority actions for the noncommunicable disease crisis. The Lancet 2011;377:1438-47.

2 Althoff T, Sosič R, Hicks JL, et al. Large-Scale physical activity data reveal worldwide activity inequality. Nature 2017;547:336-9.

3 Ewing R, Cervero R. Travel and the built environment: a meta-analysis. Journal of the American planning association 2010;76:265-94.

4 Freeman L, Neckerman K, Schwartz-Soicher O, et al. Neighborhood walkability and active travel (walking and cycling) in New York City. Journal of Urban Health 2013;90:575-85.

5 Bassett DR, Pucher J, Buehler R, et al. Walking, cycling, and obesity rates in Europe, North America, and Australia. J Phys Act Health 2008;5:795-814.

6 Cerin E, Nathan A, van Cauwenberg J, et al. The neighbourhood physical environment and active travel in older adults: a systematic review and meta-analysis. Int J Behav Nutr Phys Act 2017;14:15.

7 Garfinkel-Castro A, Kim K, Hamidi S, et al. Obesity and the built environment at different urban scales: examining the literature. Nutr Rev 2017;75:51-61.

8 Smith M, Hosking J, Woodward A, et al. Systematic literature review of built environment effects on physical activity and active transport - an update and new findings on health equity. Int J Behav Nutr Phys Act 2017; $14: 158$

9 Van Holle V, Van Cauwenberg J, Van Dyck D, et al. Relationship between neighborhood walkability and older adults' physical activity: results from the Belgian environmental physical activity study in seniors (BEPAS seniors). Int J Behav Nutr Phys Act 2014;11:110.

10 Barnett DW, Barnett A, Nathan A, et al. Built environmental correlates of older adults' total physical activity and walking: a systematic review and meta-analysis. Int J Behav Nutr Phys Act 2017;14:103.

11 Van Cauwenberg J, De Bourdeaudhuij I, De Meester F, et al. Relationship between the physical environment and physical activity in older adults: a systematic review. Health Place 2011;17:458-69.

12 Muhs CD, Clifton KJ. Do characteristics of walkable environments support bicycling? toward a definition of bicycle-supported development. Journal of Transport and Land Use 2016;9:147-88.

13 Cain KL, Millstein RA, Sallis JF, et al. Contribution of streetscape audits to explanation of physical activity in four age groups based on the microscale audit of pedestrian Streetscapes (maps). Soc Sci Med 2014;116:82-92.

14 King AC, Sallis JF, Frank LD, et al. Aging in neighborhoods differing in walkability and income: associations with physical activity and obesity in older adults. Soc Sci Med 2011;73:1525-33.

15 Corseuil MW, Schneider IJC, Silva DAS, et al. Perception of environmental obstacles to commuting physical activity in Brazilian elderly. Prev Med 2011;53:289-92.

16 Kolbe-Alexander TL, Pacheco K, Tomaz SA, et al. The relationship between the built environment and habitual levels of physical activity in South African older adults: a pilot study. BMC Public Health 2015; $15: 518$.

17 Paulo Dos Anjos Souza Barbosa J, Henrique Guerra P, de Oliveira Santos C, et al. Walkability, overweight, and obesity in adults: a systematic review of observational studies. Int J Environ Res Public Health 2019;16:3135.

18 McCormack GR, Cabaj J, Orpana $\mathrm{H}$, et al. A scoping review on the relations between urban form and health: a focus on Canadian quantitative evidence. Health Promot Chronic Dis Prev Can 2019;39:187-200.

19 Papas MA, Alberg AJ, Ewing R, et al. The built environment and obesity. Epidemiol Rev 2007;29:129-43.

20 Booth KM, Pinkston MM, Poston WSC. Obesity and the built environment. J Am Diet Assoc 2005:105:110-7.

21 Thielman J, Copes R, Rosella LC, et al. Is neighbourhood walkability related to body mass index among different age groups? A cross-sectional study of Canadian urban areas. BMJ Open 2019;9:e032475.
22 Mackenbach JD, Rutter H, Compernolle S, et al. Obesogenic environments: a systematic review of the association between the physical environment and adult weight status, the spotlight project. BMC Public Health 2014;14:233.

23 Feng J, Glass TA, Curriero FC, et al. The built environment and obesity: a systematic review of the epidemiologic evidence. Health Place 2010;16:175-90.

24 NCD Risk Factor Collaboration (NCD-RisC). Trends in adult bodymass index in 200 countries from 1975 to 2014: a pooled analysis of 1698 population-based measurement studies with $19 \cdot 2$ million participants. Lancet 2016;387:1377-96.

25 Yun S, Zhu B-P, Black W, et al. A comparison of national estimates of obesity prevalence from the behavioral risk factor surveillance system and the National health and nutrition examination survey. Int $J$ Obes 2006;30:164-70.

26 Sallis JF, Cerin E, Conway TL, et al. Physical activity in relation to urban environments in 14 cities worldwide: a cross-sectional study. Lancet 2016;387:2207-17.

27 Kerr J, Emond JA, Badland $\mathrm{H}$, et al. Perceived neighborhood environmental attributes associated with walking and cycling for transport among adult residents of 17 cities in 12 countries: the IPEN study. Environ Health Perspect 2016;124:290-8.

28 Cerin E, Cain KL, Conway TL, et al. Neighborhood environments and objectively measured physical activity in 11 countries. Med Sci Sports Exerc 2014;46:2253-64.

29 Cochrane T, Yu Y, Davey R, et al. Associations of built environment and proximity of food outlets with weight status: analysis from 14 cities in 10 countries. Prev Med 2019;129:105874.

30 Christiansen LB, Cerin E, Badland H, et al. International comparisons of the associations between objective measures of the built environment and transport-related walking and cycling: IPEN adult study. J Transp Health 2016;3:467-78.

31 Frank LD, Sallis JF, Saelens BE, et al. The development of a walkability index: application to the neighborhood quality of life study. Br J Sports Med 2010;44:924-33.

32 Stangl P. Overcoming flaws in permeability measures: modified route directness. Journal of Urbanism: International Research on Placemaking and Urban Sustainability 2019;12:1-14.

33 Tran M, Schmidt J. Walkability AUS Sicht Der Stadt-und Verkehrsplanung, in Walkability. Verlag Hans Huber: Ein Handbuch zur Bewegungsförderung in der Kommune, 2014.

34 Besser LM, Dannenberg AL. Walking to public transit: steps to help meet physical activity recommendations. Am J Prev Med 2005;29:273-80.

35 Carr LJ, Dunsiger SI, Marcus BH. Validation of walk score for estimating access to walkable amenities. Br J Sports Med 2011:45:1144-8

36 Berger K. [DHS: The Dortmund health study]. Bundesgesundheitsblatt Gesundheitsforschung Gesundheitsschutz 2012;55:816-21.

37 Erbel R, Eisele L, Moebus S, et al. Die Heinz Nixdorf recall studie. Bundesgesundheitsblatt Gesundheitsforschung Gesundheitsschutz 2012;55:809-15.

38 Greiser KH, Kluttig A, Schumann B, et al. Cardiovascular disease, risk factors and heart rate variability in the elderly general population: design and objectives of the cardiovascular disease, living and ageing in Halle (CARLA) study. BMC Cardiovasc Disord 2005;5:33.

39 Greiser KH, Kluttig A, Schumann B, et al. Cardiovascular diseases, risk factors and short-term heart rate variability in an elderly general population: the CARLA study 2002-2006. Eur J Epidemiol 2009;24:123-42.

40 Holle R, Happich M, Löwel H, et al. KORA - A Research Platform for Population Based Health Research. Gesundheitswesen 2005;67:19-25.

41 John U, Greiner B, Hensel E, et al. Study of health in Pomerania (SHIP): a health examination survey in an East German region: objectives and design. Soz Praventivmed 2001;46:186-94.

42 Völzke H, Alte D, Schmidt CO, et al. Cohort profile: the study of health in Pomerania. Int J Epidemiol 2011;40:294-307.

43 ESRI. Environmental systems research Institute 2012. 10.4 ADa, ed. Redlands, CA.

44 Lewis D, Mateos P, Longley P. Choice and the composition of general practice patient registers, 2009.

45 Stender M, Dring A, Hense H-W, et al. Vergleich zweier Methoden Zur Erhebung Der krperlichen Aktivitt. Soz Präventivmedizin 1991;36:176-83.

46 Baecke JA, Burema J, Frijters JE. A short questionnaire for the measurement of habitual physical activity in epidemiological studies. Am J Clin Nutr 1982;36:936-42.

47 Heath GW, Brownson RC, Kruger J, et al. The effectiveness of urban design and land use and transport policies and practices to 
increase physical activity: a systematic review. J Phys Act Health 2006;3:S55-76.

48 Schneider SL. Applying the ISCED-97 to the German educational qualifications. The international standard classification of education 2008:77-102.

49 Wood SN. Generalized additive models: an introduction with $R$. Chapman and Hall/CRC, 2017.

50 Burnham K, Anderson D. Model selection Multimodel inference a practical information-theoretic approach second edition. Springer New York USA, 2002.

51 Thomas D, Stram D, Dwyer J. Exposure measurement error: influence on exposure-disease. relationships and methods of correction. Annu Rev Public Health 1993;14:69-93.

52 SAS-Institute. Cary. North Carolina USA, 2017.

53 R Core Team. R: a language and environment for statisitcal computing. Vienna: R foundation for statistical computing, V. Austria, 2018. Available: https://www.R-project.org/

54 Farkas B, Wagner DJ, Nettel-Aguirre A, et al. Evidence synthesis - A systematized literature review on the associations between neighbourhood built characteristics and walking among Canadian adults. Health Promot Chronic Dis Prev Can 2019;39:1-14.

55 Van Holle V, Deforche B, Van Cauwenberg J, et al. Relationship between the physical environment and different domains of physical activity in European adults: a systematic review. BMC Public Health 2012;12:807.

56 Zapata-Diomedi B, Veerman JL. The association between built environment features and physical activity in the Australian context: a synthesis of the literature. BMC Public Health 2016;16:484.

57 Bucksch J, Schneider S. Walkability AUS Sicht Der public health in Walkability. Das Handbuch zur Bewegungsförderung in der Kommune, 2014.

58 Sugiyama T, Gunn LD, Christian H, et al. Quality of public open spaces and recreational walking. Am J Public Health 2015;105:2490-5.

59 Spinney JEL, Millward H, Scott D. Walking for transport versus recreation: a comparison of participants, timing, and locations. $J$ Phys Act Health 2012:9:153-62.

60 Frank LD, Andresen MA, Schmid TL. Obesity relationships with community design, physical activity, and time spent in cars. Am J Prev Med 2004;27:87-96.

61 Li F, Harmer PA, Cardinal BJ, et al. Built environment, adiposity, and physical activity in adults aged 50-75. Am J Prev Med 2008;35:38-46

62 Frank LD, Kerr J, Sallis JF, et al. A hierarchy of sociodemographic and environmental correlates of walking and obesity. Prev Med $2008 ; 47: 172-8$
63 Brown BB, Yamada I, Smith KR, et al. Mixed land use and walkability: variations in land use measures and relationships with BMI, overweight, and obesity. Health Place 2009;15:1130-41.

64 Zick CD, Smith KR, Fan JX, et al. Running to the store? the relationship between neighborhood environments and the risk of obesity. Soc Sci Med 2009;69:1493-500.

65 Smith KR, Brown BB, Yamada I, et al. Walkability and body mass index density, design, and new diversity measures. Am J Prev Med 2008;35:237-44.

66 Rennie KL, Johnson L, Jebb SA. Behavioural determinants of obesity. Best Pract Res Clin Endocrinol Metab 2005;19:343-58.

67 Hales CM, Fryar CD, Carroll MD, et al. Differences in obesity prevalence by demographic characteristics and urbanization level among adults in the United States, 2013-2016. JAMA 2018;319:2419-29.

68 Miller WC, Koceja DM, Hamilton EJ. A meta-analysis of the past 25 years of weight loss research using diet, exercise or diet plus exercise intervention. Int $\mathrm{J}$ Obes Relat Metab Disord 1997;21:941-7.

69 Dwyer-Lindgren L, Freedman G, Engell RE, et al. Prevalence of physical activity and obesity in US counties, 2001-2011: a road map for action. Popul Health Metr 2013;11:7.

70 Statistics Brief. Urban-Public-Transport-in-the-21th-Century, 2017.

71 Chandrabose M, Rachele JN, Gunn L, et al. Built environment and cardio-metabolic health: systematic review and meta-analysis of longitudinal studies. Obes Rev 2019;20:41-54.

72 Sehra SS, Singh J, Rai HS. A systematic study of OpenStreetMap data quality assessment. in 2014 11th International Conference on information technology: new generations. IEEE, 2014.

73 Zielstra D, Zipf A. A comparative study of proprietary geodata and volunteered geographic information for Germany. in 13th AGILE international conference on geographic information science, 2010.

74 Bock C, Diehl K. Statistische Modellierung und Verfahren, in Walkability. Verlag Hans Huber: Das Handbuch zur Bewegungsförderung in der Kommune, 2014.

75 Christiansen LB, Madsen T, Schipperijn J, et al. Variations in active transport behavior among different neighborhoods and across adult lifestages. J Transp Health 2014;1:316-25.

76 Norman GJ, Carlson JA, O'Mara S, et al. Neighborhood preference, walkability and walking in overweight/obese men. Am J Health Behav 2013;37:277-82

77 Oliver M, Witten K, Blakely T, et al. Neighbourhood built environment associations with body size in adults: mediating effects of activity and sedentariness in a cross-sectional study of new Zealand adults. BMC Public Health 2015;15:956. 